\title{
CORRELAÇÕES DE CARACTERÍSTICAS DO MEIO BIOFÍSICO DO PARQUE ES- TADUAL DE CAMPOS DO JORDÃO, SP
}

\author{
Maria de Jesus Robim! \\ Rui Marconi Pfeifer ${ }^{1}$
}

\begin{abstract}
RESUMO -É apresentado um perfil topográfico do P.E. de Campos do Jordão (Estado de São Paulo, Brasil), para o estudo das correlações entre a vegetação, "o relevo", o clima, a geologia, a geomorfologia e a pedologia. A caracterização é baseada, essencialmente, em processos fotointerpretativos e cartográficos, a fim de se verificar as correlaçōes entre os aspectos do meio biofísico, para um melhor entendimento da paisagem e preservação dos recursos naturais. Concluise que a paisagem é compartimentada, apresentando, no terço superior $(1800-2000 \mathrm{~m})$, os campos de altitude, mata latifoliada alta e baixa; no terço médio $(1600-1800 \mathrm{~m})$, os campos naturais e antrópicos, mata de Araucaria e Podocarpus, mata latifoliada com Araucaria e mata latifoliada alta e baixa e, no terço inferior (1500-1600 m), os campos naturais e antrópicos, prado e mata de Araucaria e Podocarpus.
\end{abstract}

Palavras-chave: Correlação, meio biofísico, vegetação.

\begin{abstract}
It is presented the topographic profile of the "P.E. de Campos do Jordão (São Paulo, Brasil)" to study the correlations among the vegetation, "the relief", the climate, the geology, the geomorfology and the pedology. The caracterization is essentially based on photointerpretation and cartographic processes, in order to verify the relations among aspects of biophisical environment to a better understanding of the landscape and the natural resource preservation. It concludes that the landscape is divided and it presents the altitude fields, the high and low "latifoliada" forest in the uper third $(1800-2000 \mathrm{~m})$; in the medium third $(1600-1800 \mathrm{~m})$ natural and antropic fields, the "Araucaria" and "Podocarpus" forest, "latifoliada" with "Araucaria" forest and high and low "latifoliada", forest, and, in the lower third (1500-1600 m) the natural and antropic fields, the meadows (or plains) the "Araucaria" and "Podocarpus" forest.

Key words: Correlation, Biophisical environment, Vegetation.
\end{abstract}

\section{Introdução}

Como resultado do processo da ocupação irracional do Estado de São Paulo, ocorre uma desenfreada devastação florestal e, como conseqüência, a poluição das águas, do ar e dos solos, comprometendo a qualidade de vida.

Atualmente o Estado conta com apenas 5\% de suas florestas originais (Victor 1975) e a criação de unidades de conservação é uma das soluções para garantir às gerações futuras um conhecimento da flora e fauna paulista.

Segundo Schneider (1985), no estudo de quaisquer unidades paisagísticas, deve-se referir a uma escala e a uma hierarquia funcional e especial, para que as peculiaridades de cada nivel sejam identificadas e conhecidas.

Pfeifer et al. (1987) apresentam o estudo das correlações entre pedologia, geologia, geomorfologia, relevo, declividade, clima e vegetação do Parque Estadual da Ilha do Cardoso. Concluem que a paisagem apresenta-se compartimentada: o "Maciço Montanhoso", com características que refletem um controle geológico (litológico e/ou estrutural), solos estruturados, profundos e rasos, com cobertura vegetal, em seu climax climático e a "Planície Sedimentar", com solos arenosos, de sedimentação antiga, recobertos por vegetação em seu clímax edáfico e com solos arenosos e lodosos, de sedimentação recente, recobertos por vegetação especializada, inserida em uma sucessão primária de controle edáfico.

\footnotetext{
${ }^{1}$ Instituto Florestal, Caixa Postal 1322 - 01051-São Paulo (SP)
} 
Seibert et al. (1975) elaboraram o Plano de Manejo para o Parque Estadual de Campos do Jordão levando em consideração o relevo, o clima, a geologia, a geomorfologia, os solos e a vegetação. Confeccionaram mapa da vegetação baseando-se nas formações vegetais consideradas como unidades fitofisionômicas, reconhecidas mediante observações de campo, comparações altitudinais e material de herbário.

Utilizando técnicas fotointerpretativas, Faurin (1983/1985) apresenta uma análise quantitativa das alterações da cobertura vegetal do município de Campos do Jordão, ocorridas durante o período de 1962 a 1977.

Através de estudos da unidade fitofisionômica denominada "Gleichenial", Emmerich (1980) levantou os fatores ambientais que condicionam o estabelecimento desta formação e apresentou uma listagem das principais espécies encontradas no Parque Estadual de Campos do Jordão.

Robim et al. (1986), através do levantamento florístico, apresentou uma listagem, preliminar, de 72 famílias e 115 gêneros coletados nas diversas formações vegetais do Parque de Campos do Jordão.

Modenesi (1980) estudou o intemperismo e morfogênese no planalto de Campos do Jordão. Concluiu que as características morfológicas e graus de intemperismo das formações superficiais são importantes fatores da organização do mosaico de vegetação típico dos altos campos do planalto. As matas instalam-se nos anfiteatros e nas áreas das vertentes, onde os solos são mais profundos e o regolito incoerente permite a penetração das raízes, onde os solos e, principalmente, a rocha alterada ainda apresentam uma relativa reserva de minerais primários.

Os solos do Parque Estadual de Campos do Jordão são classificados e descritos por Oliveira et al. (1975), dando conotação ao relevo, ao clima e à vegetação original, representada por campos altimontanos, floresta mista de Araucaria e Podocarpus e pela mata subtropical úmida de encosta.

\section{Material e método}

O Parque Estadual de Campos do Jordão situa-se entre os paralelos 22 $36^{\prime} 21^{\prime \prime}$ e $22^{\circ} 45^{\prime} 00^{\prime \prime}$ de latitude Sul e os meridianos $45^{\circ} 23$ '22" $245^{\circ} 31^{\prime} 34^{\prime \prime}$ de longitude W.Gr., ao norte do município de Campos do Jordão, com uma área aproximada de 8.300 ha, entre os contrafortes da Serra da Mantiqueira e a divisa com o Estado de Minas Gerais, representado na Figura 1.

No planalto de Campos do Jordão (Estação Meteorológica do DEPARTAMENTO DE ÁGUA E ENERGIA ELÉTRICA, Vila Capivari), a temperatura média anual é de $14,3^{\circ} \mathrm{C}$ (período $1973 / 1978$ ). Janeiro e fevereiro são os meses mais quentes $\left(17,5\right.$ e $17,3^{\circ} \mathrm{C}$, respectivamente), com temperaturas máximas de até $30^{\circ} \mathrm{C}$. Junho e julho, os meses mais frios $\left(10,9\right.$ e $\left.10,8^{\circ} \mathrm{C}\right)$, com mínimas de $3,2^{\circ} \mathrm{C}$. A ocorrência de geadas é comum de maio a agosto.

A pluviosidade varia muito, com totais anuais entre 1.205 e $2.298 \mathrm{~mm}$. A distribuição das chuvas, durante o ano, mostra uma concentração superior a $80 \%$ de outubro a março e um período relativamente seco no outono e inverno. Entretanto, um balanço hídrico sem deficiência garante suficiente umidade no solo, o ano inteiro. Na porção mais elevada do planalto, a influência orográfica provoca diminuição da temperatura e aumento das precipitações. A estação seca é pouco nítida.

A análise da temperatura define um clima de altitude com características de Subtropical e a distribuição da pluviosidade esboça um ritmo tropical, portanto, segundo Köppen, tipo climático $\mathrm{Cfb}$.

Nos altos campos, a distribuição da vegetação de campo e mata constitui um mosaico típico, com uma certa organização relacionada às formas de relevo, à rede de drenagem e às formações superficiais. 
No setor mamelonizado, nos topos e trechos superiores das vertentes, predominam campos de altitude. Matas ocupam o setor inferior das vertentes convexas, as vertentes retilineas e os anfiteatros de erosão.

A vegetação natural, o clima, "o relevo", o substrato rochoso e os solos são reflexos do conjunto de condições do meio biofísico marcantes na identificação da paisagem e, à nivel local, são utilizadas essas informações para identificar e correlacionar as unidades paisagisticas que possibilitam a compreensão dos diferentes sistemas ambientais existentes no P.E. de Campos do Jordão.

São utilizadas as informações contidas no Plano de Manejo do Parque Estadual de Campos do Jordão de Seibert et al. (1975) e no trabalho de Oliveira et al. (1975); fotografias aéreas verticais, na escala aproximada de 1:25.000, provenientes do vôo de recobrimento do Estado de São Paulo de 1972.

Para identificar e correlacionar os diferentes sistemas ambientais, utilizaram-se as metodologias propostas por Bertrand (1972) e Tricart (1976), que considera o meio físico um sistema dinâmico, onde seus componentes se encontram inter-relacionados.

As técnicas de trabalho de campo e fotointerpretação empregadas no reconhecimento e caracterização dos compartimentos topográficos são descritos por Modenesi (1974).

Os materiais botânicos citados estão identificados e depositados no Herbário D. Bento Pickel, do Instituto Florestal, SP (SPSF).

\section{Resultados e Discussão}

O estudo fotointerpretativo, trabalhos de campo e materiais bibliográficos, possibilitaram a elaboração da Figura 2 (Correlações de características do meio biofísico).

Concordando em Oliveira et al. (1975), o perfil topográfico apresentado compreende uma seção da área de um planalto tectonicamente elevado, com estrutura cristalina complexa. Esse planalto apresenta-se dissecado, com superfície cimeira nivelada à cerca de 2.000 metros de altitude.

O relevo associado aos fatores climáticos e pedológicos influem sobre a capacidade de infiltração, portanto, a evolução do relevo está ligada à das formações superficiais.

A temperatura da região permite qualificá-la como subtropical de altitude, porém a precipitação apresenta um ritmo tipicamente tropical, ou seja, um período chuvoso (primavera-verão) e outro seco (outono e inverno). Sendo o tipo climático classificado de acordo com o sistema de Koppen, como Cfb, sem estiagem, o excedente hídrico alimenta o deflúvio ou escoamento superficial, proporcionando o desgaste e conseqüente transporte de material.

Certas características dos solos, encontradas especialmente no terço superior, representado no perfil topográfico, parecem indicar uma tendência à latolização, confirmada pelas observações de Oliveira et al. (1975), materiais esses que, retrabalhados, podem evidenciar processos de ferralitização anteriores (depósitos de bauxita), principalmente pela acentuação pleiocênica do soerguimento do planalto.

As relações existentes entre o grau e a seqüência de alteração dos depósitos e dos materiais de origem refletem, com freqüência, os processos responsáveis pela movimentação dos materiais. Estes materiais são constatados nas rampas e nos anfiteatros.

Nas rampas, os processos rasos de coluvionamento, responsáveis pelo retrabalhamento dos materiais móveis, pouco modificam a mineralogia das formações superficiais (gnaiss e granito porfírico), enquanto que, nos anfiteatros, profundos movimentos de massa retrabalham a parte superficial, acarretando maior modificação das características mineralógicas (granito porfírico e gnaiss), onde ocorrem as associações de solo, o que concorda com Modenesi (1980).

Características da paisagem relevam que a distribuição da vegetação de campo e mata constitui um mosaico típico, com uma certa organização relacionada às formas 
de relevo e às formações superficiais.

As unidades fitofisionômicas representadas no perfil confirmam a distribuição descrita por Seibert et al. (1974) em que a mata de Araucaria e Podocarpus ocupa os fundos dos vales, as encostas com maior grau de umidade e os limites de altitude compreendimendos entre 1.500 e $1650 \mathrm{~m}$, e, em continuidade, a mata latifoliada com Araucaria, atingindo os limites de $1.700 \mathrm{~m}$.

Estas únidades intercalam-se com os campos naturais e antrópicos, que ocupam os topos dos morros, divisores de água e vertentes mais suaves. O contato é bastante brusco, não havendo uma zona de transição entre ambas (Emmerich 1980).

Através do reconhecimento de compartimentos de paisagem, nota-se uma estreita relação entre o relevo e a vegetação na qual encontra algumas espécies que concordam com o levantamento de Robim et al. (1986).

1. No terço superior $(1.800$ a $2.000 \mathrm{~m})$ encontra-se:

a) Campo de altitude - apresenta uma vegetação composta de Paepalanthus sp., Setaria sp., Panicum sp., Lavoisiera cataphracta DC; Eupatorium sp. Microlicia isophylla DC; Polygala sp., Eriocaulon sp., etc;

b) Mata latifoliada alta - com as seguintes espécies: Rapanea umbellata (Mart.) Mez., Piptocarpha axillaris Baker, Cabralea canjerana (Vell.) Mart. subsp. canjerana, Solanum variabile Mart. Weinmannia pinnata L., Pseudocaryophyllus acuminatus (Link.) Burret., Byrsonima ligustrifolia A. Juss; Roupala sp.; Eugenia involucrata DC; etc;

c) Mata latifoliada baixa - floristicamente muito semelhante à mata latifoliada alta, diferindo especialmente, pela altura dos indivíduos. As principais espécies encontradas são Croton urucurana Baill, Drimys winterii Forst; Calypthrantes sp., Pseudocaryophyllus acuminatus (Link.), Burret, Weinmannia pinnata L; Rapanea umbellata (Mart.) Mez; etc.

2. No terço médio $(1.600$ a $1.800 \mathrm{~m})$ encontra-se:

a) Campo - apresenta uma vegetação herbácea, subarbustos, arbustos e gramíneas, tais como: Achyrocline satureoides (Lamb.) DC., Baccharis myriocephala DC., Byrsonima variabilis A. Juss.; Eryngium sp.; Polygala sp.; Microlicia isophylla DC.; Campomanesia pubescens (DC.) Berg; Vernonia sp., etc;

b) Mata de Arquaria e Podocarpus - rica em Araucaria angustifolia (Bert.) O. Ktze., Podocarpus lambertii Klotzch; e outras espécies como Pronus sellowii Koehne., Drimys winterii Forst., Croton urucurana Baill., Cedrela fissilis Vell., Miconia conferta DC., Mimosa scabrella Benth Myrceugenia regnelliana (Bg.) Legr. et Kaus., Picramnia parvifolia Engl., etc.;

c) Mata latifoliada em Araucaria - no extrato superior, ao nível comum das copas, a Araucaria angustifolia (Bert.) O. Ktze. presente, sobressai. Apresenta-se também o Podocarpus lambertii Klotzch., porém as angiospermas predominam, e, floristicamente esta mata é semelhante à mata de Araucaria e Podocarpus;

d) Mata latifoliada alta - já descrita anteriormente;

e) Mata latifoliada baixa - já descrita anteriormente

3. No terço inferior $(1.500$ a $1.600 \mathrm{~m})$ encontra-se:

a) Campo - já descrito anteriormente;

b) Prado - de origem antropogênica, composto de gramineas e algumas espécies de Araucaria e Podocarpus remanescentes dos desmatamentos;

c) Mata de Araucaria e Podocarpus - já descrita anteriormente. 


\section{Conclusão}

No perfil estudado, a paisagem apresenta-se compartimentada, apresentando, no terço superior (1.800 a $2.000 \mathrm{~m})$, os campos de altitude, mata latifoliada alta e baixa; no terço médio $(1.600$ e $1.800 \mathrm{~m})$ os campos naturais e antrópicos, mata de Araucaria e Podocarpus, mata latifoliada com Araucaria e mata latifoliada alta e baixa, e, no terço inferior (1.500 a $1.600 \mathrm{~m}$ ), os campos naturais e antrópicos, prado e mata de Araucaria e Podocarpus.

Os solos apresentam-se com uma alta correlação com a geologia, isto é, no terço superior os Latossolos sobre depósitos de bauxita; no terço médio, os Cambissolos sobre gnaiss e granito porfírico e no terço inferior, as Associações indiscriminadas de solos sobre granito porfírico e gnaiss.

O perfil demonstra a existência de correlações entre os diversos fatores do meio biofísico estudados, havendo a necessidade de trabalhos mais detalhados, a fim de se detectar a influência de cada fator, nas diferentes unidades fitofisionômicas.

\section{Referências bibliográficas}

BERTRAND, G. 1972. Paisagem e geografia física global; esboço metodológico. São Paulo, USP. 27p (Caderno de Ciências da Terra, 13).

EMMERICH, W. 1980. O gleichenial como unidade fito-fisionômica. Rio de Janeiro, UFRJ. 98p. (DISSERTAÇÃO DE MESTRADO).

FAVRIN, L.J.B. 1983/1985. Levantamento da Cobertura vegetal do município de Campos do Jordão no periodo de 1962 a 1977, através de fotografias aéreas. Silvicultura, São Paulo, 17/19: 39-45.

MODENESI, M.C. 1974. Contribuição à geomorfologia da região de Itú-Salto: estudo de formações superficiais. São Paulo, USP-IGEOG. 99p. (Série Teses e Monografias, 10).

MODENESI, M.C. 1980. Intemperismo e morfogênese no planalto de Campos do Jordão, SP). Rev. Bras. Geociênc. São Paulo, 10:213-225.

OLIVEIRA, J.B.: MENK. J.R.F. ROTTA, C.C. 1975. Solos do Parque Estadual de Campos do Jordão Silvicultura, São Paulo, 9:125-155.

PFEIFER, R.M.; NOFFS, M.S. SILVA, D.A. 1987. Correlações de características do meio biofísico do Parque Estadual da Ilha do Cardoso, SP. In: CONGRESSO BRASILEIRO DE CIÊNCIA DO SOLO, 21. Campinas, jul. 12-25. Anais... São Paulo, Sociedade Brasileira de Ciências do Solo, p. 5.

ROBIM, M. de J.; AGUIAR, O.T. de; PASTORE, J.A. BAITELLO, J.B. 1986. Flora do Parque Estadual de Campos do Jordão (SP). In : CONGRESSO DA SOCIEDADE BOTÂNICA DE SÃO PAUlO, 6, Campinas, set. 22-26. Programas e resumos. São Paulo, Sociedade Botânica de São Paulo, p.30.

SCHNEIDER, M.O. 1985. Proposta para a hierarquização da paisagem no domínio dos planaltos aplainados do Brasil central. Bol. Geogr. Teor, 15 (29-30); 104-111.

SEIBERT, P.; NEGREIROS, O.C. de; BUENO, R.A.; EMMERICH, W.; MOURA NETO, B, S.F.; GUILLAUMON, J.R.; MONTAGNA, R.G.; BARRETO, R.A.A.; NOGUEIRA, J.C. B.; GARRIDO, M.A. de O.; MELLO FILHO, L.E. de; EMMERICH, M.; MARCONDES, M.A.P.; CESAR, S.F.; MATTOS, J.R. de; OLIVEIRA, M.C. de \& GODOY, A. 1975. Plano de Manejo do P.E. de Campos do Jordão. Bol. Téc. IBDF, São Paulo, (19): 148.

TRICART, J. 1976́. A geomorfologia nos estudos integrados de ordenação do meio natural. Bol. Geogr, Rio de Janeiro, 34:15 - 42.

VICTOR, M.A.M. 1975. A devastação Florestal. Silvicultura, São Paulo: 48. 


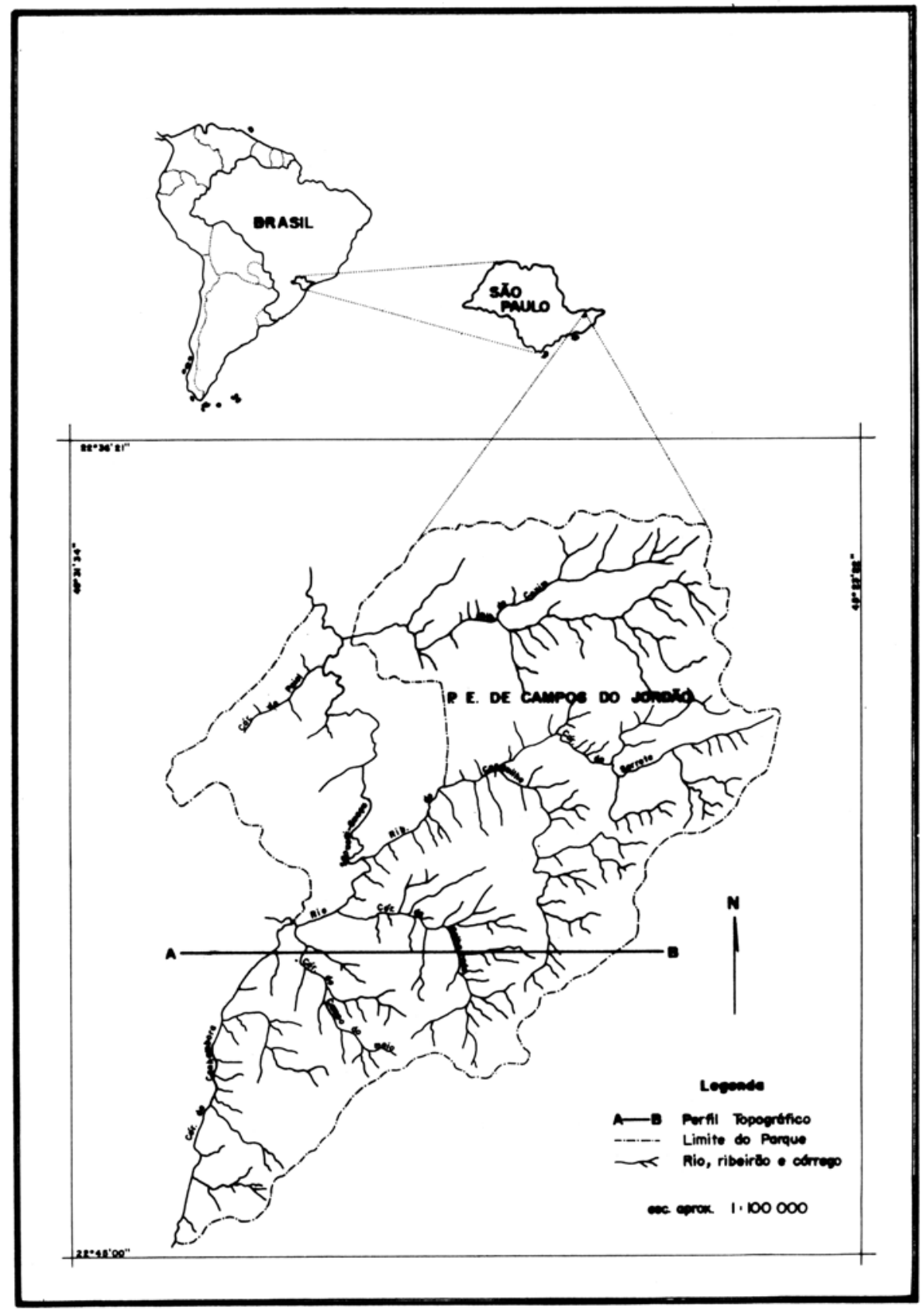

Figura 1 - Mapa de localização do P.E. de Campos do Jordão. 

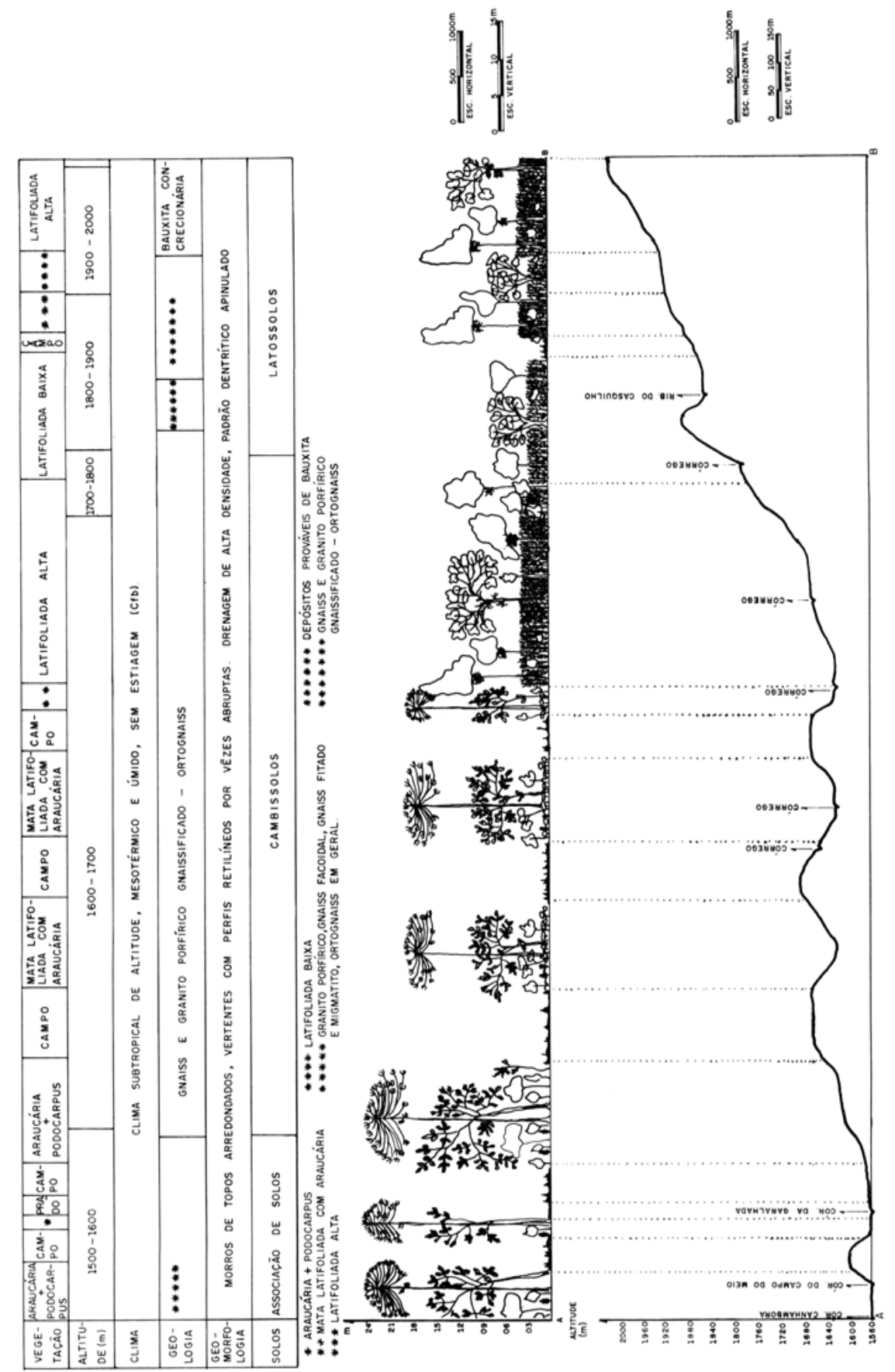

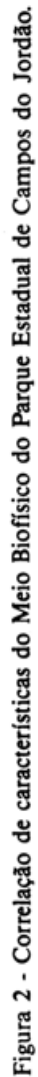

